\title{
Effect of Polymers on the Pharmaco-mechanical Properties of Direct Compressed Tablets with Ketoprofen
}

\author{
MONICA ILIUTA STAMATE ${ }^{1}$ CIPRIAN STAMATE2*, DANIEL TIMOFTE ${ }^{3 *}$, BOGDAN CIUNTU³, CARMEN GAFITANU', \\ ALINA STEFANACHE ${ }^{4}$, LACRAMIOARA OCHIUZ ${ }^{1}$ \\ ${ }^{1}$ Grigore T. Popa University of Medicine and Pharmacy, Department of Pharmaceutical Technology, 16 Universitatii Str., 700115 \\ lasi, Romania \\ ${ }^{2}$ Gheorghe Asachi Technical University, Faculty of Mechanics, 67 Mangeron Str., 700050 Iasi, Romania \\ ${ }^{3}$ Grigore T. Popa University of Medicine and Pharmacy, Department of General Surgery, 16 Universitatii Str., 700115 Iasi, Romania \\ ${ }^{4}$ Grigore T. Popa University of Medicine and Pharmacy, Department of Inorganic Chemistry, 16 Universitatii Str., 700115 Iasi, \\ Romania
}

\begin{abstract}
In this study, the effect of polymers on the mechanical properties of ketoprofen extended drug release systems were studied. Many polymers are added in formulation of compressed tablets in order to improve the physicochemical characteristics of the drug release system. The samples were made in the form of cylindrical tablet about $9 \mathrm{~mm}$ in diameter, containing different mixtures of drug substances and excipients acording to seven formulations. Cylindrical tablets containing mixtures of ketoprofen and various types of polymers are made by direct compression method. Among the binders used were a series of different polymers like Kollidon va 64, hydroxypropyl methyl cellulose and sodium carboxyl methyl cellulose. Mechanical parameters such as hardness, mechanical strenght, friability and roughness were studied in order to determine how they are influenced by polymeric binders.
\end{abstract}

Keywords: polymers, compressed tablet, hardeness, roughness

The preparation of tablets is based on the judicious choice of the ingredients and their owners: the drug substance, the excipients, the auxiliary substances and the packaging containers, as well as the pharmaceutical operations constituted in a technological stream. The formulation of the drug and the manufacturing process mustensure the desired quality of the pharmaceutical form and its reproducibility under the conditions of the industrial preparation.

The rational choice of the physicochemical and biopharmaceutical properties of the drug and the excipients as well as the stages of the manufacturing process are only the qualitative element of the formulation. At present, there is a question of optimizing the formulation in quantitative terms, that is, the quantity of an excipient and the parameters of the technological process [1]. At this stage, the substances (for pharmaceutical use) to be studied are determined, in which case the active substance with therapeutic effect is ketoprofen and the excipients are specific for direct compression.

Ketoprofen is an active principle belonging to the analgesic-antipyretic-anti-inflammatory group, where the anti-inflammatory effect prevails. This drug removes or diminishes some symptoms and signs of inflammation in rheumatic diseases [2]. Ketoprofen is hepatically metabolised and has a half-life of 2 hours to $2 \mathrm{~h}$ and 15 minutes for conventional forms, and for sustained-release pharmaceutical forms of $5 \mathrm{~h}$ and $15 \mathrm{~min}$. The therapeutic blood concentrations are reached within $30 \mathrm{~min}$, and the maximum levels occur after $2 \mathrm{~h}$ after oral administration, $4 \mathrm{~h}$ after rectal application and within 15-45 min after intramuscular administration. The minimal effective concentration of ketoprofen is reached within $45 \mathrm{~min}$ to one hour after ingestion of the prolonged release tablet. Concentrations of ketoprofen in synovial fluid persist more than serum concentrations. The excretion of ketoprofen is renal in excess of $80 \%$ initially as conjugated glucuronide.
It is indicated in the symptomatic treatment of inflammatory rheumatism, especially rheumatoid arthritis, ankylosing spondylitis, symptomatic treatment of acute cases of arthrosis (coxarthrosis, gonarthrosis) and acute postmenopausal dysmenorrhea, bone pain in tumor metastases, gout, pseudogut, extraarticular rheumatism (tendinitis and bursitis) [2-4]. Contraindications refer to known allergies to ketoprofen or other non-steroidal inflammatory drugs, evolved gastroduodenal ulcer, severe hepatic impairment, severe renal impairment and pregnancy.

Kollidon VA 64 (copolyvidone or copovidone according to $\mathrm{Ph}$. Eur.) Copolymer between vinylpyrrolidone and vinyl acetate is considered to be one of the best dry binders successfully used in direct compression. It is an excipient that can produce high hardness tablets even under the conditions of a low compression force by direct compression, low-cost, low-energy, and low-energy process $[5,6]$. The much improved assortment has a high degree of fineness, increased plasticity and increased ability to bind dry matter. Small size and high plasticity make Kollidon VA 64 an efficient binder, a single molecule of collidone that binds 6 molecules of pure active compound or mixture. Kollidon ${ }^{\circledR}$ VA 64 can be added to various formulations in association with materials such as sorbitol, mannitol and starch for direct compression along with microcrystalline cellulose in order to obtine tablets with very good mechanical properties.

Sodium carboxymethyl cellulose (croscarmellose) is a crosslinked polymer being a highly hydrophilic, highly absorbent material having excellent swelling properties due to its fibrous nature which gives it excellent water absorption capabilities. Croscarmellose provides good dissolution and disintegration characteristics, thus improving the bioavailability of the drug in the formulation. In the case of the formulation of prolonged release tablets, the association of various retarding agents could lead to $a$

*email: cip101301@gmail.com; dantimofte@yahoo.com; bogdanmciuntu@yahoo.com 
deficiency in the dissolution of the tablet at different levels of the digestive tract, so that the use of croscarmellose improves this behavior by providing optimal dissolution and erosion-disintegration of the tablets [5-8].

Hydroxypropyl methylcellulose (HPMC K4M) known as nonionic cellulose ether is one of the most important polymers used in the preparation of modified release forms. This polymer forms hydrophilic matrices that control the release of the drug by molecular relaxation and diffusion. In combination with sodium carboxymethyl cellulose, it can provide controlled drug release of the pharmaceutical form by controlled erosion.

Sorbitol is a polyol (sugar alcohol), is a bulk sweetener found in many foods. Frequently used as a sweetener is also an excellent wetting and texturing agent. Crystalline sorbitol grades have been specially developed in terms of particle size distribution, flow properties and minimization of compression force required for direct compression applications. The characteristics of the sweetener, the nonreactivity and the compatibility with the active ingredients make sorbitol an ideal constituent in various pharmaceutical formulations to improve the taste, flow properties and uniformity of tablet mass [9-13].

Magnesium stearate, also called octadecanoic acid, magnesium salt, is a white, solid substance at room temperature. This is a salt that contains two equivalent fractions of stearate (anion of stearic acid) and one of magnesium cations $\left(\mathrm{Mg}^{2+}\right)$. Magnesium stearate melts at about $88^{\circ} \mathrm{C}$, is not soluble in water and is often used as a slider in the manufacture of tablets, capsules and powders. For this purpose, the substance is also useful because it has lubricating properties, preventing sticking of the powder mixture to the manufacturing equipment during direct compression. magnesium stearate is the most commonly used tablet lubricant $[14,15,18]$.

The aim of this study was to assess the influence of polymers on the pharmaco-mechanical properties of the prolonged release tablets with ketoprofen.

\section{Experimental part}

\section{Materials and methods}

A typical compressed tablet contains a mixture of one or more active pharmaceutical ingredients with a number of inactive ingredients identified as excipients. In this study were used: Ketoprofen supplied by Bidachem, Italy; binders like hydroxypropyl methylcellulose (HPMC) Methocel ${ }^{\circledR}$ K100 (Colorcon, United Kingdom); sodium carboxymethyl cellulose (CMC) (Ashland, USA); and Kollidon-64-VA, diluents like Sorbitol (BASF, Germany); and lubricants like magnesium stearate - Kemilub $®$ (Undesa, Spain). Seven ketoprofen matrix tablets were formulated and prepared through direct compression method using a Korsch EKO tablet press with two flat punches with punch diameter of $9 \mathrm{~mm}$ and at compression force of $12 \mathrm{kN}$.

The surfaces of the die and punches were lubricated with magnesium stearate powder prior to each compaction. The powder was weighed on an analytical balance and manually filled into the die. As a result, a tablet is a mechanical system consisting of various bonded functional and structural parts. The spatial distribution of active pharmaceutical ingredients and excipients in a tablet play critical roles in defining its performance as a drug delivery device. Also, structural tablet defects like pharmaceutical functional irregularities in active pharmaceutical ingredients can therefore affect the primary therapeutic functions of a tablet.

The first step in this study is the determination of weight (w) variation. According to the $10^{\text {th }}$ Romanian Pharmacopoeia twenty tablets were randomly selected from each formulation, individually weighed and the average weight of 20 tablets was calculated.

Thickness $(g)$ and diameter $(d)$ of ten randomly selected tablets were determined using a digital micrometer.

Mechanical parameters of the tablets are tensile strength and friability but they depend on the bulk parameters like: volume, density of powders, Hausner ratio and compressibility index.

Bulk and tapped density were determined by pouring the blend into a graduated cylinder. (1):

The bulk density $\left(\rho_{\mathrm{b}}\right)$ was calculated using the equation

$$
\rho_{b}=\mathrm{M} / \mathrm{V}_{\mathrm{b}},
$$

where: $\mathrm{Vb}$ is bulk volume, $\mathrm{M}$ is the weight of the powder [17].

Tapped Density $\left(\rho_{\mathrm{t}}\right)$ was determined by pouring blend and tapped into a graduated measuring cylinder for a fixed time. The tapped density is the ratio between minimum volume (Vt) occupied in the cylinder and the weight (M) of the blend and was calculated using the equation (2):

$$
\rho_{\mathrm{t}}=\mathrm{M} / \mathrm{V}_{\mathrm{t}}
$$

Compressibilityindex (I) depends on the tapped density and bulk density and was calculated using following equation (3):

$$
I=\left[\left(\rho_{t}-\rho_{b}\right) / \rho_{t}\right] \cdot 100,
$$

where: $\left(\rho_{0}\right)$ is tapped density, $\left(\rho_{\mathrm{b}}\right)$ is bulk density the value below $15 \%$ indicates a powder which usually gives good flow characteristics; where above $25 \%$ indicates poor flow ability $[15,16]$.

Hausner's Ratio $(H)$ is an indirect index of powder flow. It is given by the following equation (4).

$$
\mathrm{H}=\rho_{\mathrm{t}}-\rho_{\mathrm{b}},
$$

where: $\left(\rho_{t}\right)$ is tapped density and $\left(\rho_{b}\right)$ is bulk density. Lower Hausner's ratio $(<1.25)$ indicates better flow properties than higher ones $(>1.25)$.

Hardness or tablet crushing strength $(p)$ represent the force required to break a tablet in a diametric compression. When a tablet is subjected to a force, the response can be interpreted on the basis of the bond summation or fracture mechanics concepts. In the bond summation concept, the bonds holding the particles together and the breakage of these bonds during strength testing are emphasized. In the fracture mechanics concept, focus is on the propagation of cracks in the tablet during strength testing. There are several methods for measuring the mechanical strength of tablets, e.g. the breaking strength, diametrically compression and axial mechanical strength $[19,20]$. The most common strength testin pharmaceutical applications is the diametrically compression test, which is used to calculate the radial mechanical strength of a tablet and was measured using a Pharma-Test tablet hardness tester. Ten tablets were used in each determination.

The mechanical strength ( $t$ ) of pharmaceutical tablets is a function depending on the hardness, diameter and thickness of tablet and can be characterized by the force necessary to break the tablet. Mechanical strength of tablets was calculated using (5):

$$
\mathrm{T}=2 \mathrm{P} / \pi \mathrm{Dt},
$$

where: $(p)$ is the load needed to fracture the tablet, $(t)$ is the thickness and (d) the diameter of the tablet [1].

Friability (f) of tablets was determined using Electrolabfriability-tester with a otating drum chamber (25rpm). The tablets were weighed and placed in the friabilator chamber where the tablets make a sliding motion on the surface of the drum. The test infolves 100 slightly rotation and after 
that the tablets were cleaned with a soft muslin cloth and reweighed.

Friability of tablets represents a percentage of weight loss and was calculated using equation 6 :

$$
\mathrm{F}=\left[\left(\mathrm{W}_{\mathrm{f}}-\mathrm{W}_{\mathrm{i}}\right) / \mathrm{W}_{\mathrm{f}}\right] \times 100,
$$

were: $W_{i}$ is the initial weight of tablets and $W_{f}$ is the final weight of tablets after friability test.

Due to the fact that compressed pharmaceutical forms are obtained bycompressing pow ders atmicroscopic level, the surface of these tablets is characterized by a roughness specific to each type of formulation, which has an essential role in the quality control and wettability of the surface tablets [21, 22].

Another important parameter is the roughness and its measurements were made with the Form Talysurf Intra 50 rugosimeter, a portable instrument with an interchangeable fingerprint, designed to measure and analyze the texture and shape of different surfaces $[23,24]$. The maximum scan length of the cross-sectional area is $50 \mathrm{~mm}$. For the determination of profile and roughness parameters, 112/ $20092 \mu \mathrm{m}$ Standard Conical Diamond was used with the peak radius of $2 \mu \mathrm{m}$ and the $90^{\circ}$ peak angle. The device consists of a main displacement system mounted on a horizontal table sliding on a vertical layout cross member. The tablet to be examined for roughness is placed on the work table and fixed on it and then the touch probe is brought into contact with the sample. At the same time, an automatic program for automatic detection of the highest point on the spherical autocrest ball was run. Running this program resulted in the maximum height on the $X$ axis and its position on the $Y$ axis. As compared to this central point, the left touch probe was programmed with $-12 \mathrm{~mm}$, then it was defined as the new point of origin in the surface scan. By removing the touch probe at a distance of $9 \mathrm{~mm}$, such as the diameter of the tablet, the roughness of the tablet was recorded.

\section{Results and discussions}

The formulas (F1-F7) used for each set of tablets have the same concentrations of ketoprofen like active ingredient and different concentrations of polymeric excipients, according to the table 1.

The binders like Kollidon and HPMC K100M powders were mixed in various ration to obtain powders with different plastoelasticity. For each formulation were tested tw enty tablets and the results express the average values of each parameter. The results of tablets testing are exhibited in (table 2).

Table 1

FORMULATION OF KETOPROFEN PROLONGED RELEASE MATRIX TABLETS

\begin{tabular}{|c|c|c|c|c|c|c|c|}
\hline \multirow[t]{2}{*}{ Ingredients } & \multicolumn{7}{|c|}{ Quantity (mg/tablet) } \\
\hline & Fl & F2 & F3 & F4 & F5 & F6 & F7 \\
\hline Ketoprofen & 150 & 150 & 150 & 150 & 150 & 150 & 150 \\
\hline Kollidon & $30^{-}$ & $40^{\circ}$ & 60 & - & - & - & 30 \\
\hline $\begin{array}{l}\text { Hydroxypropyl methylceluloze (HPMC } \\
\text { K100M) }\end{array}$ & - & - & - & 30 & 40 & 60 & 30 \\
\hline Microcrystaline cellulose & 34 & 24 & $14^{-}$ & 34 & 24 & 14 & $14^{--}$ \\
\hline Sodium carboxymethyl celluloze (CMC) & 34 & 24 & 14 & 34 & $24^{-}$ & 14 & 14 \\
\hline Sorbitol & 1.2 & 1.2 & 1.2 & 1.2 & 1.2 & 1.2 & 1.2 \\
\hline Magnezium stearate & 1.8 & 1.8 & 1.8 & 1.8 & 1.8 & 1.8 & 1.8 \\
\hline Totalitablet (mg) & 250 & 250 & 250 & 250 & 250 & $250^{\circ}$ & 250 \\
\hline
\end{tabular}

Table 2

THE VALUES OF PHARMACO-MECHANICAL PARAMETERS

\begin{tabular}{|c|c|c|c|c|c|c|c|}
\hline \multirow[t]{2}{*}{ Parameters } & \multicolumn{7}{|c|}{ Tablet formula } \\
\hline & F1 & F2 & F3 & $\mathrm{F} 4$ & F5 & F6 & F7 \\
\hline Density $(\mathrm{g} / \mathrm{mL})$ & $0.43 \pm 0.01$ & $0.52 \pm 0.01$ & $0.62 \pm 0.01$ & $0.43 \pm 0.01$ & $0.66 \pm 0.01$ & $0.56 \pm 0.01$ & $0.75 \pm 0.01$ \\
\hline $\begin{array}{l}\text { Taped density } \\
(\mathrm{g} / \mathrm{mL})\end{array}$ & $0.51=0.02$ & $0.41=0.04$ & $0.52=0.06$ & $0.54=0.02$ & $0.72 \pm 0.03$ & $0.68 \pm 0.07$ & $0.59=0.02$ \\
\hline $\begin{array}{l}\text { Hausners ratio } \\
(\mathrm{g} / \mathrm{mL})\end{array}$ & $0.08 \pm 0.01$ & $0.11=0.03$ & $0.10 \pm 0.04$ & $0.11 \pm 0.01$ & $0.06 \pm 0.02$ & $0.12 \pm 0.04$ & $0.16 \pm 0.01$ \\
\hline $\begin{array}{l}\text { Compressibility } \\
\text { index }(\%)\end{array}$ & $15.68 \pm 0.01^{-}$ & $26.82=0.02$ & $19.23=0.03$ & $20.37 \pm 0.01$ & $8.33 \pm 0.02$ & $17.64 \pm 0.05$ & $27.11=0.01$ \\
\hline Thickness (mm) & $2.01=0.03$ & $2.02=0.07$ & $2.03=0.10$ & $2.02 \pm 0.06$ & $1.85 \pm 0.02$ & $1.97 \pm 0.04$ & $1.97 \pm 0.04$ \\
\hline Diameter (mm) & $9.01=0.02$ & $9.01=0.02$ & $9.02=0.02$ & $9.03=0.02$ & $9.02 \pm 0.02$ & $9.02=0.02$ & $9.02 \pm 0.02$ \\
\hline Hardness (N) & $70 \pm 1.42$ & $72 \pm 1.02$ & $75 \pm 1,32$ & $110=1.02$ & $128 \pm 1,12^{-}$ & $145 \pm 1.02$ & $98 \pm 0,02$ \\
\hline $\begin{array}{l}\text { Mechanical } \\
\text { strength }\left(\mathrm{N} / \mathrm{mm}^{2}\right)\end{array}$ & $2.46 \pm 0.02$ & $2.51 \pm 0.03$ & $2.60 \pm 0.01$ & $3.84 \pm 0.02$ & $4.88 \pm 0.01$ & $5.19=0.03$ & $3.51=0.02$ \\
\hline Friability $(\%)$ & $0.79^{-}$ & 0.75 & $0.54^{-}$ & 0.38 & 0.26 & 0.17 & 0.44 \\
\hline
\end{tabular}


The tensile strength and hardness values for tablets formulation $\mathrm{F} 5$ and $\mathrm{F} 6$ were generally high thus displaying the characteristics of plastic compression. The formulation F1 and F2 displayed the characteristics of elastic compression with low tensile strength and hardness values. The difference in the response of the tablets to the mechanical tests relates to the difference in the plastoelasticity of the materials. Amorphous binders like hydroxypropyl methylcelulose which undergo pronounced plastic deformation provide a large surface area available for particles bonding.

Breaking strength increases with increasing thickness of tablets and the number of bridges between particles. An excipient with plastic behavior will cause a small thickness of the sample and higher hardness (F5 and F6). Excipients with elastic behavior lead to a thicker sample due to partial relaxation of elastic connections, after removing the compression strength and hardness decreases (F1 and F2).

Tensile strength increases with increasing hardness and diameter samples (F5 and F6). The results suggested that this high mechanical strength occurs due to the bonds between different particles are stronger than those between the same types of particles (F5).

Furthermore, in relation to fracture mechanics, the addition of a plastically deforming material can act as a crack stopper which will prevent crack propagation. Friability is a parameter that depends on the mass of sample lost to friction with a smooth surface. Lost weight the sample depends on the quality of connections between particles. As bonds are so strong mass loss is lower and brittle decreases (F5).

The friability depend the degree of plastic compression witch decreased as the proportion of binders in the powder mixture. An elastic binder (Kollidon) lowers the plastic compression and increased friability (F1).

For the roughness analysis, only the tablet formulations having the lowest friability value at the maximum binder concentration were selected. The analysis of the surface roughness of the tablets is shown in figure 3 where they are presented: the scanned surface profile with the corresponding dimensions and the profile specific to the roughness with the amplitude of the signal on the axis, in microns. All important roughness parameters are automatically calculated by the Form Talysurf Intra 50 and displayed in the table of the image.

As the pharmaceutical tests have already confirmed, for the F7 formula the degree of compaction is superior to the other two and the roughness confirms this by the reduced profile peaks (fig. 1). The presence of the two polymers, Kollidon and hydroxypropyl methyl cellulose in large quantities, leads to an increased degree of powder packaging and reduced roughness. For the other formulas, the profile changes by recording several high peaks indicating a high roughness (figs. 2 and 3). Increased roughness is responsible for damage to tablet surfaces by erosion on contact with conditioning material, resulting in loss of drug. A low roughness shows us a uniform surface due to a compact particle organization that had enough sliders for space ordering and enough compaction polymers to bond the particles to each other. Wetting and absorption on these rough surfaces should be much stronger, but this depends on the distribution of hydrophilic polymers on the surface of the tablet. The roughness has little or no influence on the wettability of the tablets, which depends most on the degree of hydrophilicity of the matrix-forming polymers.

The presence in tabletformulation of the Kollidon in the high percentage, results in an increased roughness due to a lower packing of powders that is beneficial when we associate with compact matrix-forming polymers that are difficult to penetrate from the fluid biological environment.

Also, as previolsy mentioned, these aspects could exert an increased range of applications in the literature and for a wide range of patients [25], considering also our previous experience in the pharmacological [26,27], toxicological [28], biochemical [29] or molecular [30] context.

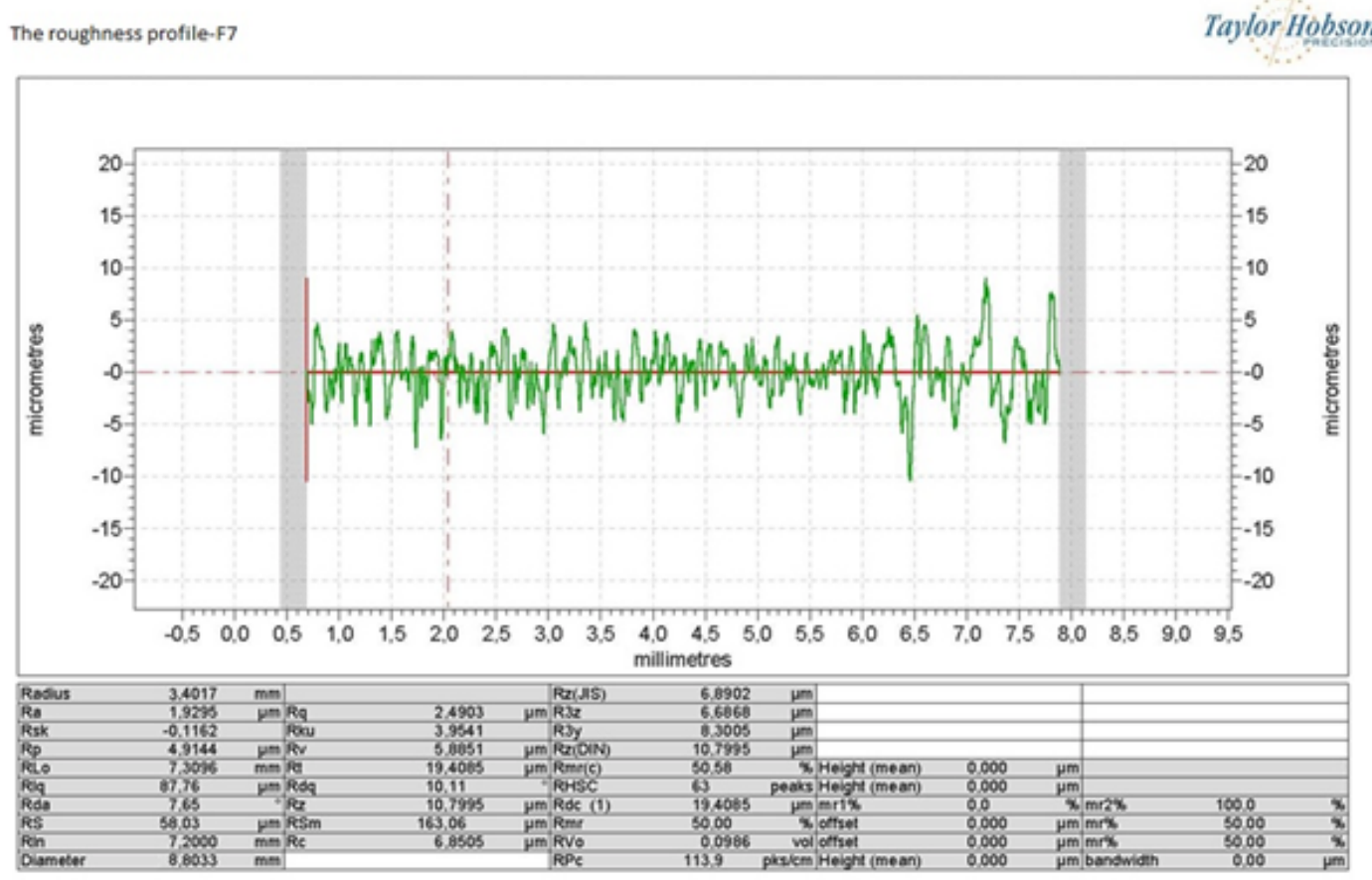

Fig. 1. The roughness profile of the F6 tablets 


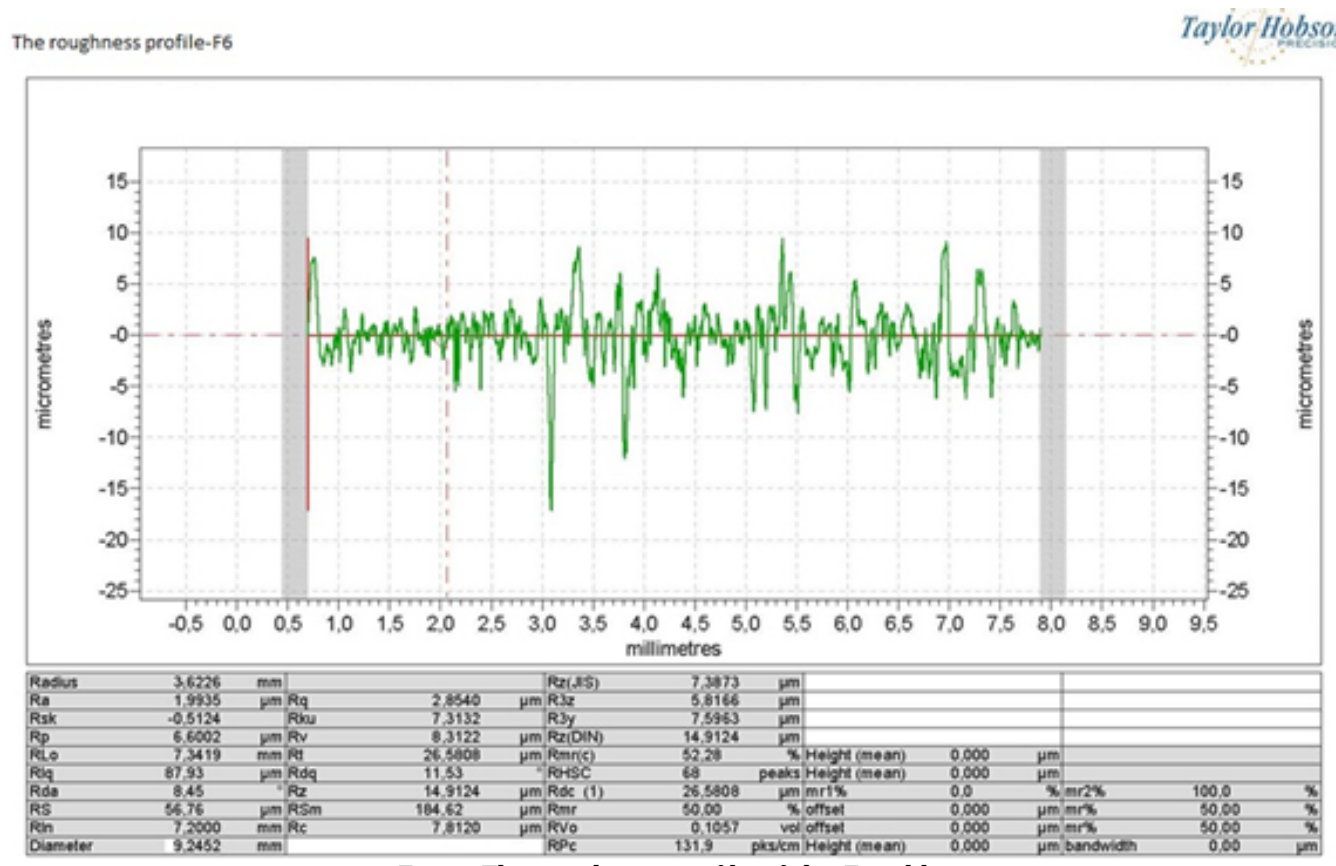

Fig. 2. The roughness profile of the F6 tablets

$\begin{array}{ll}\text { The roughness profile-F3 } & \text { Taylor Hobso: }\end{array}$

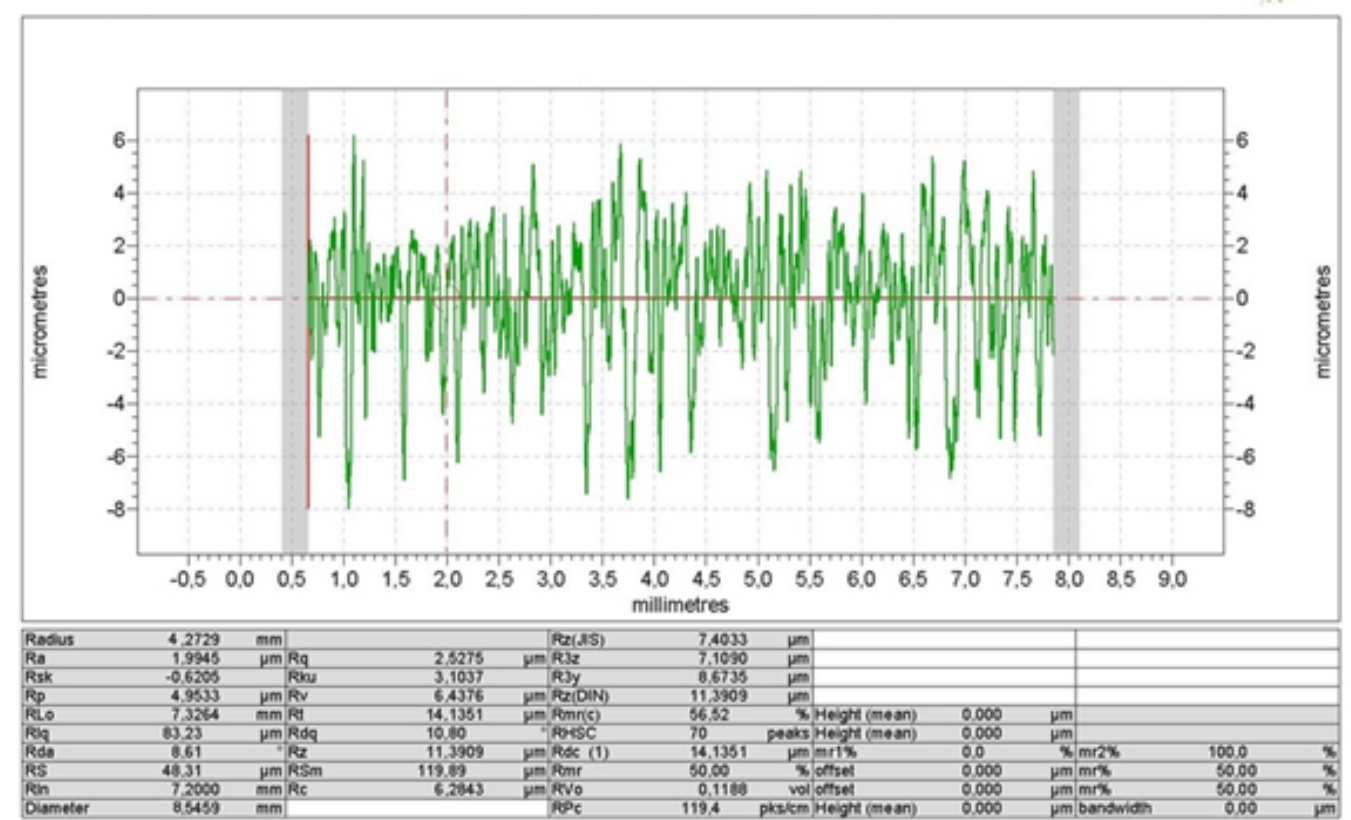

Fig. 3. The roughness profile of the F3 tablets

\section{Conclusions}

The physical characteristics of studied tablets provided good weight uniformity and hardness. Each of the polymers used, with different excipients, yielded matrix tablets with a hardness value ranging from 70 to $145 \mathrm{~N}$. It was also observed that a variation in the tablet hardness was accompanied by an obvious change in tablet tensile strength. Because the polymers presence the tablets also passed the friability test $(\mathrm{F}<1 \%$ ) showing that all formulations are within the pharmacopoeias limits. The roughness decrease with increasing of polymers percentages, a balanced polymer composition leads to a low roughness and a low risk of tablet surface damage. Based on all the formulations studied, ketoprofen matrix tablet containing polymers in high proportion, F3 and F6, respectively, showed excelent mechanical properties. The present results provide useful information on the type of polymers and additives that should be employed on the formulation of direct compressed tablets, in order to obtaine prolonged release tablets with uniform surfaces (low roughness) and optimal pharmaco-mechanical characteristic.

\section{References}

1.HANSON, P.D., MADDISON, J.E., Nonsteroidal anti-inflammatory drugs and chondroprotective agents, Chapter 13, Small Animal Clinical Pharmacology, Second Edition., 2008, p. 286-308.

2.POPOVICI, I., LUPULEASA, D., Tehnologie Farmaceuticã, vol. III, Ed. Polirom, Bucuresti, 2009, pp. 621-625.

3.HIMI, M., MAURYA, S.D., Journal of Drug Delivery \& Therapeutics. 3, no. 2, 2013, p. 131.

4.DAS, N., International Journal of Pharmacy and Pharmaceutical Sciences. 5, 2013, p. 112.

5.MAJI, P., GANDHI, A., JANA, S., MAJI, N., J ournal of PharmaSciTech, 2(2), 2013, p. 62-67. 
6.VERGNAUD, J.M., ROSCA, I.D., Assessing Bioavailability of Drug Delivery Systems. Taylor \& Francis Group, LLC, United States of America, 2005, p. 74-75.

7.GENNARO, A.R., Remington: The Science and Practice of Pharmacy, University of Science Philadelphia, 2000, p. 654-699.

8.CRISTEA, A.N., Farmacologie generala, ed a-II-a, Ed. Didactica si Pedagogica, R.A., 2009, p. 162, 228.

9.AKHGARI, A., ABBASPOUR, M.R., REZAEE, S., KUCHAK, A., J. Nat. Pharm. Prod., 6, 2011, 51-58.

10.BHARATE, S.S., VISHWAKARMA, R.A., Expert Opin. Drug Deliv., 10, 2013, p. 1239.

11..SHOAIB, M.H., TAZEEN, J., HAMID, A., YOUSUF, R., Pak. J. Pharm. Sci. 19, no. 2, 2006, p.119.

12.CRETAN, S.M., GAFITANU, C., STAMATE, C., GAFITANU, E., Interantional Proceedings of Computer Science and Information Technology, 4, 2011, p. 310.

13.LEUCUTA, S.E., Biofarmacie si farmacocinetica, Ed. Dacia, ClujNapoca, 2002.

14.CHUGHISHA, S.N., RANA, A.C., GUPTA, S., Int. Res. J. Pharm., 3, no. 5, 2012; p. 57.

15.DAHAN, A., MILLER, J.M., AAPS J . 14, 2012, p. 244.

16.GAD, S.C. United States Pharmacopoeia (USP). Encyclopedia of Toxicology, 3rd ed.; Wexler, P., Ed.; Academic Press: Oxford, UK, 2014; p. 881-882.

17.PATEL, H., PANCHAL DHRUPESH, R., PATEL, U., TUSHAR, B., MAYUR S., Journal of Pharmaceutical Science and Bioscientific Research, 1, no. 3, 2011, p. 143.

18.SAWYNOK, J., Topical Analgesics. In Clinical Pain Management: A Practical Guide; Lynch, M.E., Ed.; Wiley-Blackwell, Toronto, ON, Canada, 2010, p. 135-141.

19.TAPASWI, R.D., PANKAJ, V., International Journal of Pharma Research \& Review, 2, no. 2, 2013, p. 12.
20.YARCE, C., PINEDA, D., CORREA, C., SAlAmanCA, C., Pharmaceuticals, 9, 2016, p. 34.

21.ZHAI, C., GAN, Y., HANAOR, D., PROUST, G., RETRAINT, D., Experimental Mechanics, 56, no. 3, 2016, p. 359.

22.CRETEANU, A., STEFANACHE, A., VIERIU, M., TANTARU, G., OCHIUZ, L., Rev. Chim. (Bucharest), 70, no. 1, 2019, p. 1.

23.HANAOR, D., GAN, Y., EINAV, I., Tribology International, 93, 2016, p. 229.

24.CONFEDERAT, L., MOTRESCU, I., CONSTANTIN, S., LUPASCU, F., PROFIRE, L., Rev. Chim. (Bucharest), 69, no. 7, 2018, p. 1756.

25.CIOBICA, A., PADURARIU, M., CIOBICA, A., TIMOFTE, D., STEFANESCU, C., NASREDDINE, Z., International journal of geriatric psychiatry, 32, no. 1, 2017, p. 116-117.

26.OCHIUZ, L., GRIGORAS, C., POPA, M., STOLERIU, I., MUNTEANU, C., TIMOFTE, D., PROFIRE, L., GRIGORAS, A.G., Molecules, 21, no 7, 2016, p. 858.

27.GRADINARU, I., TIMOFTE, D., VASINCU, D., TELSOIANU, D., CIMPOESU, R., MANOLE, V., GHEUCA-SOLOVASTRU, L., Mat. Plast., 51. no 3, 2014, p. 230-234.

28.DUMBRAVA, D., ; RADU, C., IOV, T., DAMIAN, S., SANDU, I., TIMOFTE, D., CHIROBAN, O., Rev. Chim. (Bucharest), 69, no. 7, 2018, p. 18891891.

29.TROFIN, F., CIOBICA, A., HONCERIU, C., COJOCARU, S., STOICA, B., COJ OCARU, D., CIORNEA, E., TIMOFTE, D., Romanian biotechnological letters, 22, no. 2, 2017, p. 12439-12447.

30.AURSULESEI, V., VASINCU, D., TIMOFTE, D., VRAJ ITORIU, L., GATU, I., IACOB, D., GHIZDOVAT, V., BUZEA, C., AGOP, M., General physiology and biophysics, 35, no 3, 2016, p. 287-298.

Manuscript received: 16.12 .2018 